\title{
An Evidence-Based Review of E-HRM and Strategic Human Re- source Management
}

\author{
Janet H. Marler, University at Albany-State University of New York, USA \\ marlerealbany.edu \\ Sandra L. Fisher, Clarkson University, USA \\ sfisher@clarkson.edu
}

\begin{abstract}
One stated purpose of electronic human resource management (eHRM) is to make the entire HRM function more strategic. The goal of this paper is to examine recent research in e-HRM to evaluate the cumulated evidence on the relationship between strategic HRM and e-HRM, and to provide evidence-based guidance to practitioners and researchers. Specifically, we examine evidence of a relationship between e-HRM and strategic $H R$, the direction of the relationship, and the resources or contexts important for the e-HRM and strategic HR relationship to exist. We review 20 studies published from 2007-2009 using integrative synthesis as our evidence-based methodology. Results reveal that few e-HRM empirical studies have explicitly examined strategic issues. Less than half the studies are at a macro-level of analysis, which is a key distinguishing feature of research conducted in the strategic HRM domain. Furthermore, most research only examines the relationship between e-HRM and perceived strategic effectiveness of HRM. None directly examine other strategic outcomes. Our review highlights the need for more empirical studies on eHRM and strategic HRM outcomes at a macro level.
\end{abstract}

Keywords: e-HRM; Strategic HRM, Evidence-Based Management; HRIS; HRM.

\section{Introduction}

Both strategic human resource management and electronic human resource management (e-HRM) are relatively new research streams. Strategic HRM literature emerged about 30 years ago [17] and early e-HRM studies begin appearing around 1995 [39]. Interestingly, both research streams invoke potentially transformational outcomes for the role of human resource management within organizations. In the strategic HRM literature, scholars focus on strategic outcomes such as organizational performance [3], strategic alignment [37], and competitive advantage [48]. In the e-HRM literature, researchers expect internet-based technological innovations to assist in realizing the outcomes predicted in the strategic HRM literature. Organizational goals for e-HRM investments include cost reduction through streamlining HRM operations [22],

Strohmeier, S.; Diederichsen, A. (Eds.), Evidence-Based e-HRM? On the way to rigorous and relevant research, Proceedings of the Third European Academic Workshop on electronic Human Resource Management, Bamberg, Germany, May 20-21, 2010, CEUR-WS.org, ISSN 1613-0073, Vol. 570, online: CEUR-WS.org/Vol-570/, pp. 33-51.

(C) 2010 for the individual papers by the papers' authors. Copying permitted only for private and academic purposes. This volume is published and copyrighted by its editors. 
improved effectiveness through providing better delivery of HRM services [34] and transformation of the HRM function to a strategic business partner [20].

Given the prominent role accorded strategic outcomes in the e-HRM literature, it is important that researchers and practitioners have a clear picture of the accumulated research evidence to date on this presumed relationship. The purpose of this study therefore is to apply an integrative evidence-based framework [33] to examine recent empirical studies on e-HRM to identify scientific research evidence concerning the nature of e-HRM's association with strategic HRM. We also review these papers to ascertain what e-HRM and strategic outcome relationships are supported across studies and what resources or contexts are important for e-HRM to be associated with strategic outcomes and to be accepted and used by stakeholders.

After presenting definitions of strategic HRM and e-HRM, in section 3, we present our evidence-based methodology for systematically selecting our sample of published empirical and case study evidence linking e-HRM and strategic HRM. We apply this methodology to direct our analysis of the evidence presented in our sample of published research in section 4 . In the final section, we synthesize the evidence, noting common themes, gaps in our knowledge, and lessons learned.

\section{Conceptualizing Strategic HRM and e-HRM}

\subsection{What is Strategic HRM}

An early and widely accepted definition of strategic HRM is that it is "the pattern of planned human resource deployments and activities intended to enable an organization to achieve its goals." [49] A more recently proposed definition, derived from a growing body of research, reflects a more expansive perspective. Synthesizing multiple strategic HRM models including the universalistic [31], contingent [36-37, 49] configurational [18, 49] and contextual [25] perspectives, Martin-Alcazar, Romero-Fernandez and Sanchez-Gardy [25] define strategic HRM as "the integrated set of practices, policies and strategies through which organizations manage their human capital that influences and is influenced by the business strategy, the organizational context and the socioeconomic context." This latter definition sets the strategic HRM phenomena in a broader context emphasizing important influential factors beyond the organization.

Lepak \& Shaw's [19] literature review of strategic HRM in North America builds on the latter definition. They identify several specific distinguishing features of strategic HRM. First, strategic HRM is a macro-level concept and thus further specify the concept of organization to mean at a company, business unit or establishment level. Second, strategic HRM highlights the notion of fit among HRM practices, known as horizontal alignment, and vertical fit between HRM and other organizational factors, typically business strategy. Third, strategic HRM focuses on HRM systems, a bundle of HR practices that are either universally, contingently, or configurationally effective depending on espoused theoretical perspective. Finally, strategic HRM emphasizes organizational performance outcomes.

Lengnick-Hall and colleagues' (2009)[17] also contribute to an increased understanding of what the strategic HRM domain comprises. In a comprehensive chronological review of the strategic HRM literature, they identify three chronological stages. Early strategic HRM literature emphasized a contingency perspective in which fit between human resource policies and practices and various strategy elements was the focal point. Consequences of strategic HRM in this stream of research included organizational 
performance contingent on vertical fit or predicted bundles of HRM practices based on intended business strategy. Thus this literature focused on describing the phenomena in terms of bundles of practices and the fit of HRM practices with each other and with other organizational contexts such as business strategy.

A second line of inquiry focused on strategic HRM as a source of important strategic contributions. Consequences of strategic HRM in this stream shifted focus from employee welfare as the key outcome to competitive advantage, human capital, social capital, organizational capital, intellectual capital and knowledge management as key outcomes. The focus of this stream of literature was on outcomes of the strategic HRM phenomena and the notion that the outcomes determined whether the HRM input was strategic.

More recently, another line of research emphasizes the importance of effective execution of HR policies and practices and ensuring that the strategic intent is realized. In this newer stream, divergence between intended and implemented strategic HRM practices are explored and suggest the possibility that the expected outcomes of a strategic HRM intervention might depend on what actually is implemented.

\subsection{What is e-HRM}

Several definitions of e-HRM exist in the academic literature. The two most cited definitions are provided by Strohmeier [39] [40][41] and Ruel and colleagues [34]. Ruel, Bondarouk and Looise [34] proposed an early popular definition in which e-HRM was defined as a way of implementing HRM strategies, policies and practices in organizations through the conscious and directed support of and with the full use of web technology based channels. Strohmeier [39] expanded this definition to be more specific about the technological and organizational contexts, defining e-HRM as the application of information technology for both networking and supporting at least two individual or collective actors in their shared performing of HR activities. In the remainder of the paper, we use a hybrid of these definitions in which e-HRM consists of intended and actual HRM policies, activities, services, and collaborations with individuals and organizations, which are delivered and enabled using configurations of computer hardware, software, and electronic networking capability.

\section{Research Framework and Methodology}

In this study, we use integrative synthesis which is an accepted evidence-based methodology to summarize the existing research literature [33]. Integrative synthesis involves the collection and comparison of evidence involving two or more data collection methods [33]. It investigates patterns across primary research studies, compensating for single-study weaknesses in research design to improve the internal and external validity of the various research findings. Integrative synthesis typically employs predetermined questions and selection criteria. Critical selection criteria include the relevance and construct validity of indicators obtained by different methods, all tapping what is presumed to be the same phenomenon. This method often pursues multiple questions allowing the review to address issues difficult to examine in the context of a single study. Integrative synthesis is not meta-analysis. It relies on judgment of the researchers, but around a structured framework and set of questions.

Below we define our research methodology in detail following the procedure described by Rousseau and colleagues, and Dibbern and colleagues [8, 33]. We begin first with identifying our predetermined questions and follow with our selection criteria. Our 
selection criteria involved first specifying key construct search terms to identify relevant studies. We then specified factors that would insure relevance and construct relevance. Finally, we categorized each selected study by its theoretical foundations, type of relationship examined (e.g., type of validity), level of analysis, and empirical approach. We discuss this methodological process in more detail in the following subsections.

\subsection{Integrative synthesis questions}

Typical questions framing an integrative synthesis relate to effectiveness of interventions and cause-effect relationships. The key question framing our integrative synthesis is: What e-HRM and strategic HRM relationships are present and supported across studies? In our review of the evidence addressing this question, we examine the nature of the relationship between these two constructs. What does the evidence suggest concerning the causal order of the relationship? Does the evidence suggest e-HRM is the cause or consequence of strategic HRM outcomes [40]? Does the evidence support a deterministic view in which technology triggers organizational change or does the evidence suggest a more influential role for social and organizational actors $[12,28]$ ? We also note how strategic HRM is conceptualized. Is it based on early stage theories, on strategic outcomes of strategic HRM, or later concerns with the juxtaposition of intended versus realized strategic outcomes? Finally, our synthesis addresses the feasibility of applying the findings from this literature. We therefore also examine what resources or contexts are important for the e-HRM and strategic HRM relationship to exist. What do stakeholders (HR managers, managers, employees, vendors, shareholders) experience and what issues are important to them?

\subsection{Sample Selection}

To identify an appropriate sample of published research evidence to include in our integrative synthesis, we started by searching for all published articles related to e-HRM in the past ten years (1999-2009). We searched in the primary business and psychology indexed databases, utilizing ABI Inform/Proquest, Business Source Premier, and PsycArticles. We developed an extensive list of search terms used in the field. Table 1 presents the search terms used and the number of articles identified using each of the search terms. Articles were coded based on the search term with which they were first located. Several of the articles were matched with multiple search terms but we did not code the additional matching search terms. Ten additional articles were identified by scanning reference lists of recently published research [e.g., Strohmeier, 2009]. In total, we identified 77 published research articles related to e-HRM.

In the next step, we applied several criteria to identify the set of articles most relevant to our research questions. We decided to retain only those articles that (1) were in peer reviewed publications, (2) included quantitative or qualitative data (no purely conceptual studies), (3) fit one or more definitions of e-HRM as reviewed above, (4) addressed the use of e-HRM in an organizational setting rather than taking a pedagogical approach of teaching students about e-HRM, and (5) were published in the same year or after Strohmeier's [39] recent literature review (2007 - 2009). At this stage, we did not consider the extent to which the articles addressed strategic HRM.

This screening process resulted in 20 articles that met all criteria. Our review of these articles is organized first by stated or implicit strategic HR perspective, thus addressing our key question. In the case of articles with an implicit strategic HR perspective, we used our judgement based on a close reading of the article to categorize any underlying presumed relationship. In most cases, although not the main focus of the paper, a 
presumed relationship between e-HRM and strategic HRM is a stated justification for or implication of the research.

Then we discuss evidence by theoretical foundation, type of statistical relationship, level of analysis, and empirical approach. Articles included in the review are categorized in Table 2. Note that the column totals within a category (e.g., strategic HR perspective) do not necessarily add to 20 because some of the articles were categorized into multiple categories.

\subsection{Strategic HR perspective}

We organized our sample of e-HRM published studies by Lengnick-Hall et al.'s [17] chronological stages of strategic HRM research. Research in e-HRM that takes the contingency perspective examines a potential fit between different organizational characteristics and the use of e-HRM, either overall adoption or the use of different types or elements of e-HRM. Research founded in the strategic contributions stage examines strategic outcomes and thus the specific strategic outcomes or consequences associated with e-HRM. Finally, research in the third stage examines consistency or divergence between the intended and implemented HRM practices, and how the intended or presumed strategic impact could be limited by implementation problems. Much of the prior research in individual-level adoption of e-HRM technology is at this third stage. We also identified studies that simply focused on contextual factors that might affect whether intended outcomes are actually realized.

\begin{tabular}{|l|l|}
\hline Search Term & Number of Articles Identified \\
\hline B2E and HRM & 1 \\
\hline e-HR & 6 \\
\hline e-HRM & 6 \\
\hline ERP and HRM & 2 \\
\hline HRIS & 31 \\
\hline HRM and Internet & 4 \\
\hline Self-service & 7 \\
\hline Virtual HRM & 1 \\
\hline Web-based HRM & 11 \\
\hline
\end{tabular}

Table 1: Articles Identified Using Specified Search Terms

\subsection{Theoretical foundation}

Since our key questions involve investigating the types of relationships evidenced between e-HRM and strategic HR we categorized each study based on the theory used to develop the research model/hypotheses. Relevant theoretical foundations are found in the strategy, information sciences and strategic HRM literatures. Key theories in the 
strategy research that are relevant to the e-HRM and strategic HR relationship include contingency theory, the resource-based view, and strategic evolution, value chain theories, and institutional theory. Theories from information science include technological determinism [28, 40], structuration theory [12], innovation diffusion theories [32], technology acceptance theories [6, 45], and information processing theory. Theories applied to strategic HRM include configurational and universalistic theories and behavioral theory [7, 15, 18, 31, 38, 47]. We looked to see if the research was based on a single theory or multiple theories, and also included an unspecified "other" category in our framework to cover other theories or unexpected findings, which provoked alternative theoretical explanations.

\subsection{Type of relationship}

For research to effectively inform evidence based management, we must be confident in the conclusions drawn from the study. There are four types of relationships between key constructs that research must address in order to meet satisfactory empirical standards. These four relationships are typically referred to as conclusion validity, internal validity, construct validity, and external validity. Conclusion validity establishes whether there is a relationship between two constructs. Internal validity establishes whether this relationship is causal and if so the direction of causality. Construct validity investigates whether measurement of the key constructs is sufficient to adequately assess the relationship. Finally external validity establishes how generalizable the relationship is and whether there are contextual contingencies that might affect the observed relationship. We classified our sample of studies by the type of relationship that received the most attention. 


\begin{tabular}{|c|c|c|c|c|c|c|c|c|c|c|c|c|c|c|c|c|c|c|c|c|c|c|c|c|c|c|c|c|}
\hline Study & Explicit & $\begin{array}{ll}\text { Strate } \\
\end{array}$ & gic $\mathrm{HR}$ & Perspec & & & eory? & & & rateg & & & $\frac{\mathrm{R}}{\mathrm{format}}$ & $\begin{array}{l}\text { Referer } \\
\text { tion S } \\
\end{array}$ & icienc & $\begin{array}{l}\text { Theory } \\
\text { ce }\end{array}$ & \begin{tabular}{|l|l} 
Orga \\
\end{tabular} & anizatior & nal Scie & \begin{tabular}{l|l} 
& P \\
nce & \\
\end{tabular} & Relations & & $\begin{array}{r}\text { Level } \\
\text { Analy }\end{array}$ & $\begin{array}{l}\text { ll of } \\
\text { ysis }\end{array}$ & Emp & írical A & Approa & \\
\hline & & 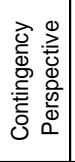 & 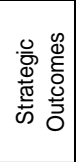 & 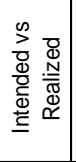 & 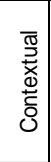 & 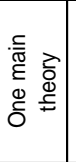 & $\begin{array}{l}\frac{0}{0} \\
\frac{0}{3} \\
\Sigma\end{array}$ & $\stackrel{0}{\frac{0}{0}}$ & $\begin{array}{l}\overrightarrow{0} \\
\overline{0} \\
\overline{0} \\
\stackrel{\bar{c}}{\mathbf{c}} \\
\overline{0} \\
0\end{array}$ & 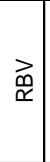 & 离 & 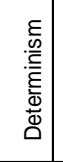 & 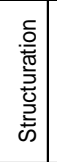 & $\sum_{1}$ & 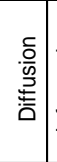 & 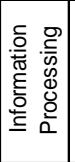 & $\mid$ & 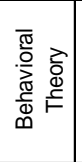 & 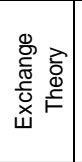 & 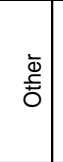 & 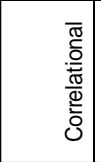 & $\begin{array}{l}\overline{\widetilde{J}} \\
\overline{\widetilde{J}} \\
\widetilde{J}\end{array}$ & $\begin{array}{l}\frac{0}{0} \\
\overline{0} \\
\Sigma\end{array}$ & $\stackrel{\circ}{\stackrel{\circ}{\grave{L}}}$ & 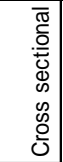 & & 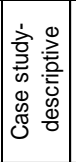 & 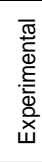 \\
\hline Teo, Lim, and Fedric & $x$ & & $x$ & & & $x$ & & & & & & & & & $x$ & & & & & & $x$ & & $x$ & & $x$ & & & \\
\hline Ruel, Bondarouk, and Van der Velde & $\mathrm{x}$ & $x$ & $\mathrm{x}$ & & & & $\mathrm{x}$ & & $x$ & & & & & $x$ & & & & & & & $\mathrm{x}$ & $x$ & & $\mathrm{x}$ & $\mathrm{x}$ & & & \\
\hline Hussain, Wallace and Cornelius & $\mathrm{x}$ & $\mathrm{x}$ & $x$ & $\mathrm{x}$ & $x$ & $x$ & & & $x$ & & & & & & & & & & & & $\mathrm{x}$ & & $\mathrm{x}$ & & $\mathrm{x}$ & & & \\
\hline Olivas-Lujan, Ramirez, \& Zapata-Cantu & & & & $x$ & $x$ & & & $\mathrm{x}$ & & & & & & & & & & & & & & & $x$ & & & & $x$ & \\
\hline Allen, Mahto, and Otondo & & & & $\mathrm{x}$ & & & $\mathrm{x}$ & & & & & & & $\mathrm{x}$ & & & & & & $\mathrm{x}$ & & $\mathrm{x}$ & & $\mathrm{x}$ & & & & $\mathrm{x}$ \\
\hline Dineen, Ling, Ash, and DelVecchio & & & & $x$ & & & $x$ & & & & & & & & & & & & & $\mathrm{x}$ & & $\mathrm{x}$ & & $x$ & & & & $\mathrm{x}$ \\
\hline Tansley and Newell (JMP) & & & & $\mathrm{x}$ & & & $\mathrm{x}$ & & & & & & & & & & & & $\mathrm{x}$ & & & & & $\mathrm{x}$ & & & $x$ & \\
\hline Tansley and Newell (ML) & & & & $\mathrm{x}$ & & & $x$ & & & & & & & & & & & & & $x$ & & & & $\mathrm{x}$ & & & $x$ & \\
\hline Alleyne, Kakabadse and Kakabadse & & & $x$ & & & & $x$ & & & & & & & & & & & & & $\mathrm{x}$ & & & & $x$ & & & $x$ & \\
\hline Panayotopoulou, Vakola, and Galanaki & & $x$ & $x$ & & & & & $\mathrm{x}$ & & & & & & & & & & & & & & & $x$ & & $x$ & & & \\
\hline Voermans and Van Veldhoven & $\mathrm{x}$ & $\mathrm{x}$ & & & & & $\mathrm{x}$ & & $x$ & & & & & $\mathrm{x}$ & & & & & & & $\mathrm{x}$ & $\mathrm{x}$ & & $\mathrm{x}$ & $\mathrm{x}$ & & & \\
\hline TOTAL 2007 & 4 & 4 & 5 & 6 & 2 & 2 & 7 & 2 & 3 & 0 & 0 & 0 & 0 & 3 & 1 & 0 & 0 & 0 & 1 & 4 & 4 & 4 & 4 & 7 & 5 & 0 & 4 & 2 \\
\hline \begin{tabular}{|l} 
Haines and Lafleur \\
\end{tabular} & $x$ & $x$ & $x$ & & & & $x$ & & & & & $\mathrm{x}$ & $x$ & & & $x$ & & & & & $x$ & & $x$ & & $x$ & & & \\
\hline \begin{tabular}{|l} 
Lukaszewski, Stone, and Stone-Romero \\
\end{tabular} & & & & $x$ & & & $x$ & & & & & & & & & & & $\bar{x}$ & & & & $x$ & & $x$ & & & & $x$ \\
\hline Ngai, Law, Chan and Wat & $\bar{x}$ & & $x$ & & $x$ & & & $x$ & & & & & & & & & & & & & $x$ & & $x$ & & $x$ & & & \\
\hline TOTAL 2008 & 2 & 1 & 2 & 1 & 1 & 0 & 2 & 1 & 0 & 0 & 0 & 1 & 1 & 0 & 0 & 1 & 0 & 1 & 0 & 0 & 2 & 1 & 2 & 1 & 2 & 0 & 0 & 1 \\
\hline Dineen and Noe & & & & $\mathrm{x}$ & & & $x$ & & & & & & & & & & & & & $x$ & & $x$ & & $x$ & & & & $\mathrm{x}$ \\
\hline $\begin{array}{l}\text { Payne, Horner, Boswell, Schroeder, and } \\
\text { Stine-Cheyne }\end{array}$ & & & & $\mathrm{x}$ & & $\mathrm{x}$ & & & & & & & & & & & & $\mathrm{x}$ & & & & $x$ & & $x$ & & $\mathrm{x}$ & & \\
\hline Strohmeier and Kabst & & & & & $x$ & & $x$ & & & & & & & $x$ & $x$ & & & & & $\mathrm{x}$ & $x$ & & $x$ & & $x$ & & & \\
\hline Marler, Fisher, and Ke & & & & & $x$ & $x$ & & & & & & & & $x$ & & & & & $x$ & & $x$ & $x$ & & $x$ & $x$ & $x$ & & \\
\hline Farndale, Paauwe, and Hoeksema & $\mathrm{x}$ & $x$ & $\mathrm{x}$ & & & & & $x$ & & $x$ & & & & & & & & & & $x$ & & & $\mathrm{x}$ & & & & $\mathrm{x}$ & \\
\hline Bondarouk, Ruël, and van der Heijden & $x$ & $x$ & $x$ & & & & $x$ & & & & & & & $x$ & & & & & & & & $x$ & & $x$ & & & $x$ & \\
\hline TOTAL 2009 & 2 & 2 & 2 & 2 & 2 & 2 & 3 & 1 & 0 & 1 & 0 & 0 & 0 & 3 & 1 & 0 & 0 & 1 & 1 & 3 & 2 & 4 & 2 & 4 & 2 & 2 & 2 & 1 \\
\hline OVERALL TOTALS & 8 & 7 & 9 & 9 & 5 & 4 & 12 & 4 & 3 & 1 & & & & 6 & 2 & 1 & 0 & 2 & 2 & & & 9 & & 12 & & & 6 & \\
\hline
\end{tabular}

Table 2: Descriptive Analyses of Empirical Studies 


\subsection{Levels of analysis and empirical approach}

Next we chose to examine the key relationships by the levels of analysis addressed in the research and then by empirical approach used to verify the type of theorized relationship within level. The level of analysis used in any study should be clearly linked to the theoretical foundation.

To adequately address the question of strategic HR, constructs of interest should be at the firm, division, or some other unit at the organizational level. Research in e-HRM may also be at the group, team or department level, examining group-level social constructs or perhaps differences between groups in implementation of new technology.

Then we evaluated the empirical approach used to verify the expected relationships within the specified level of analysis. Cross sectional samples and variance-based statistical analyses help establish conclusion validity, construct validity and external validity. Longitudinal samples, experimental designs and process-based statistical analyses better establish causal relationships or internal validity.

\section{Literature Review and Analysis}

The first finding of note is that less than half of the empirical research, eight out of twenty studies, conducted on e-HRM over the past several years has explicitly addressed strategic relationships or outcomes. The majority presumed some kind of strategic relationship. Based on Lengnick-Hall et al.'s [17] framework, we identified seven articles adopt a contingency perspective and nine that evaluated strategic outcomes associated with e-HRM. In some cases, we counted a study as both a contingency perspective and a strategic outcome when the strategic outcome represented HRM strategic effectiveness. Nine articles examined consistency or divergence between the intended and implemented HRM practices, and five focused on contextual factors that might affect whether intended outcomes are actually realized (note that some of the articles incorporated more than one perspective). In the last two categories, strategic outcomes were often implied or offered as a reason for conducting the research but were not directly examined in the study. We continued to assess all of the studies with our complete research framework to determine how the findings of these studies might inform practitioners and future research on the relationship between e-HRM and strategic HRM.

Six studies in our sample explicitly examined the relationship between perceptions of eHRM effectiveness and perceptions of the HR function's strategic effectiveness and strategic business partner role. These studies presented a strategic contingent theoretical perspective with the underlying assumption that HR managers that provide strategic support to line managers also support the organization in reaching strategic objectives. E-HRM in these studies enables the HR function to become more strategically effective as described by Huselid, Jackson and Schuler [15].

Of the nine studies in the sample categorized as dealing with strategic outcomes, none provided explicit evidence concerning other strategic outcomes (e.g. improved human capital, competitive advantage, business performance) beyond improving perceptions of HRM's strategic effectiveness. Less than half of the studies $(n=8)$ were conducted at the organizational level of analysis. 


\subsection{E-HRM and strategic HR: contingency perspective}

To date, the literature on e-HRM and strategic HRM assumes a contingent theoretical perspective in which the perceptual relationship between these two constructs is most frequently studied. Six of the studies we reviewed provide evidence of a significant relationship between individual perceptions (e.g. employees, HR managers, line managers, senior executives) of e-HRM effectiveness and perceptions of the strategic effectiveness of the HRM function. The second most common approach treats e-HRM as the cause of business process improvements that are assumed to be related to more effective, potentially more strategic, HRM practices.

Ruel, Bondarouk and Van der Velde [35] conduct a field study to determine whether an employee's assessment of various characteristics of e-HRM is related to perceptions of HRM's strategic effectiveness. Their study integrated Huselid and colleagues' measure of strategic HRM effectiveness within a technology acceptance model theoretical framework[5]. They surveyed 100 employees of the Dutch Ministry of Internal Affairs and found that employee participation in the development stage of e-HRM implementation predicted employee perceptions of e-HRM quality. They also found that e-HRM quality predicted employee perceptions of strategic HRM effectiveness. Similar to Ruel and colleagues, Voermans and van Veldhoven's [46] study of 356 Dutch employees of Philips, a Dutch multinational, provided additional evidence of a link between attitude toward e-HRM and perceptions of the quality of HRM as a strategic business partner.

Haines and Lafleur [13] surveyed Canadian HR managers across 210 firms to assess the relationship between the degree IT supported HR activities and HR managers' perceptions of HR's technical and strategic effectiveness. They found a positive relationship between the degree of IT support of HR activities and HR manager's perceptions of the organization's HR strategic effectiveness, and with the quality of HR's strategic and change agent roles as assessed using Ulrich and Brockbank's measure of strategic business partner and change agent role performance [44].

Hussain, Wallace, and Cornelius [16] found that slightly less than 50\% of a random sample of companies in the UK use HRIS or other software exclusively in support of strategic HR usage tasks ${ }^{1}$. They claim their findings reveal wholesale adoption of HRIS in support of a full strategic partnering role, regardless of company size. Their results show, however, that while surveyed HR professionals believed that the usage of HRIS for strategic decision-making led to enhanced professional standing within and outside the organization, semi-structured follow-up interviews with organizational executives revealed a less positive assessment. Senior executives thought that HRIS use had not enhanced HR's professional standing within the organization, contrary to the views of HR managers' themselves.

Two very recent studies, however, suggest that expectations that e-HRM enables or supports HR managers in taking on more strategic business partner tasks are not founded $[4,11]$. In a qualitative case study of an e-HRM module deployed in the Dutch Ministry of the Interior, Bondarouk and colleagues [4] found that line managers and employees did not appear to link e-HRM functionality with HRM strategic effectiveness. E-HRM made administrative/data management more accessible but it did not improve the line managers' or employees' perception of HRM being more

\footnotetext{
${ }^{1}$ Although they did not measure e-HRM specifically, we assume at least some of the HRIS fits the
} 
strategically effective. Ironically, the semi-structured interviews of managers and employees suggested HR managers continued to misdirect their efforts on nonemployee value-added activities such as cost reduction and re-organization. Farndale Paauwe and Hoeksema [11] also found the deployment of an electronically enabled HR shared service centre resulted in less use of local HR generalists by line managers, contrary to the authors' expectation that the technology would free HR employees to spend more time strategically supporting line managers.

\subsection{E-HRM and strategic outcomes}

As described above, some studies examined perceptions of HR managers' strategic effectiveness or strategic business partner roles. However, none of the studies looked at whether e-HRM was related to other strategic outcomes such as competitive advantage, organizational performance, or improved HR outcomes such as increased human capital, reduced turnover or increased organizational commitment or job satisfaction. Instead the existing studies focus on factors one step removed from such strategic outcomes.

Ruel et al.'s [35] theoretical frame had an underlying deterministic presumption, which was that e-HRM would facilitate the strategic transformation of the HR function. However, they also examined whether the degree to which managers were involved in adapting the e-HRM at implementation predicted managerial perceptions of HRM's strategic effectiveness. Although they did not test whether perceptions of the quality of the e-HRM acted as a mediator, their study design implies that perceptions of e-HRM quality are an important outcome of potential strategic significance. Thus they treat eHRM effectiveness, the mediating construct, as both an effect and a cause. It is an effect of managerial involvement in implementing e-HRM and it is a cause of managerial perceptions of HRM's strategic effectiveness.

Alleyn, Kakabadse and Kakabadse [2] take a novel approach by applying the customer service satisfaction profit chain [14] model combined with the concept of met expectations to argue that satisfaction with e-HRM technology will result in line manager satisfaction (line managers are HR's internal customers). The implication here is that by developing satisfied line managers who are HR customers, e-HRM is thus related to eventual greater productivity and retention of line managers. Their interviews suggest that when line managers' expectations of the e-HRM are met they express satisfaction with e-HRM and their satisfaction with the HR function increases. On the other hand, unmet expectations resulted in dissatisfaction with both the e-HRM and the HRM function overall.

\subsection{E-HRM as the strategic outcome: an alternate causal ordering}

In a review of early e-HRM consequences, Strohmeier [40] calls into question the appropriateness of assuming a deterministic view of e-HRM in which e-HRM determines organizational outcomes. He argues the causal ordering could be reversed and thus suggests that e-HRM itself is the result of strategic decision-making. With this perspective, researchers are focused on understanding what social agents and contextual factors determine how a technology is developed and designed and whether and how it is deployed. Thus e-HRM is a strategic outcome of strategic HR and not the other way around.

Haines and Lafleur [13] also argue that outcomes of IT do not deterministically change an organization but depend on the extent to which IT is viewed as useful and thus 
adopted and adapted to improve organizational information processing capability. Hussain, Wallace and Cornelius [16] argue that strategic pressure on the HR function within organizations is implicated in HR managers' use of HRIS to improve their strategic decision making capability and professional image within the organization. This theoretical perspective presumes e-HRM is the outcome of strategic choices on the part of HR managers with the intended effect of improving their strategic capability and image.

Two exploratory studies, one of firms in Hong Kong [26] and one of firms located in Greece [29] examined reasons why firms used e-HRM. Both studies found the key reason related to improving communication between HR and employees and between managers and employees. Strategic outcomes were of secondary importance and generally related to achieving reduced HR costs. Teo, Lim and Fedric (2007) examined e-HRM adoption as an outcome among firms located in Singapore. They looked to see if innovation, organizational, and environmental characteristics of the firm would impact adoption of e-HRM systems. Findings suggested that the organizational characteristics were related to adoption while the more strategic predictors such as competitive pressure were not.

In a very recent study Farndale, et al. [11] explored HR shared service centres (SSC) used by 15 firms located in the Netherlands. They argue that a SSC is a natural progression of e-HRM technologies because SSC are characterized by electronic communications through an internet-based infrastructure that is combined with a call center, enabling the consolidation of corporate activities into fewer locations while spreading information to a broader audience. As Farndale and colleagues note, "a shared-service centre is not an end in itself; it is a means to transforming the whole function of HR to make it more strategic....Ultimately, the decision to create an SSC is largely a factor of corporate strategy. The decision to bring HRM administrative tasks in a single location to provide services across business divisions or locations indicates a certain desire on behalf of the organization to consolidate its field of operations.[11]" Thus the deployment of e-HRM represents an outcome of a corporate strategy to consolidate HRM administrative tasks with the primary objective to improve customer (e.g., manager and employee) service at reduced costs.

\subsection{E-HRM and strategic HRM: Intended vs. realized implementation}

In this section, we examine the extent to which strategic intent of e-HRM technology was effectively implemented. As noted by Tansley and Newell, the strategic intent for e-HRM may be present, but there are many complications in system development and implementation that may stand in the way of effective use [44, 45]. Nine of the papers directly shed light on this part of our question. The two case studies by Tansley and Newell provided a detailed context for understanding, for those who have never been involved in implementation of e-HRM, how complex the process really is. They studied two different development teams to examine factors that can help these teams realize the intended goals of e-HRM. They found that leadership competencies were very important, such as the ability to bring together individuals from different role perspectives (e.g., IT and HR). Project leaders in this context must be able to identify, manage and dispel political issues that have potential to derail the project.

The experimental and quasi-experimental papers included in our review [1,9-10, 21] offer a different perspective on the intended/realized question. These papers sought to examine the effectiveness of specific aspects of the e-HRM systems (recruiting, performance appraisal, and broader HR data storage) in a controlled environment to see 
if they had the intended effects before implementing the systems more broadly. Three papers examined the use of e-HRM to improve recruiting outcomes [1, 9-10]. Allen, Mahto and Otondo conducted an experimental study looking at how the amount of information presented to potential job applicants would affect attitudes toward the organization and subsequently, intentions to apply for a position. Dineen and colleagues [9-10] also examined information provided to potential job applicants, focusing on provision of customized information from a person-organization and person-job fit perspective. All of these studies found that appropriate, active use of technology could be used to enhance applicant interest in a job or organization, or even enhance the quality of the overall applicant pool by providing customized data about personorganization and person-job fit. Another paper examined implementation of an online performance appraisal (PA) system (Payne, et al.)[30]. This was a quasi-experimental study in a large organization that looked at perceptions of a new online performance appraisal system compared to a more traditional system. This study found that with the online system employees perceived managers to be held more accountable and employees reported participating more in the process, two indicators of a more effective PA system. However, Payne, et al. also found employees were equally satisfied with the paper and pencil and online systems, and actually reported that the online appraisals were of lower quality than the paper and pencil ones received the previous year. This was certainly not an intended goal of the organization.

Lukaszewski et al. [21] examined privacy concerns with e-HRM data storage. They found that employees had greater concerns about the privacy of data stored in an eHRM system when data sensitivity was higher (e.g., with medical data). This is another unintended outcome that needs to be examined further.

\section{5 e-HRM and strategic HRM : Contextual factors}

Another common theme in many of these studies is that there are important contextual factors upon which e-HRM acceptance and use by stakeholders depends. Although these contextual factors were often not the specific focus of the study, several researchers concluded that e-HRM acceptance by stakeholders depends on degree of involvement in design and implementation of e-HRM $[2,35]$; the perceived usefulness of the e-HRM technology [23-24, 46]; whether expectations were met [2]; degree of managerial coercion [23] on training/ perceived organizational resources [24, 46] and finally to perceptions of privacy or data security related to acceptance of e-HRM, with inconsistent results $[21,30]$. We discuss these findings because e-HRM certainly cannot achieve strategic outcomes if it is not accepted and used by stakeholders. In addition to factors that might affect e-HRM acceptance, several studies identified contexts or resources important for e-HRM to be associated with strategic outcomes. These contextual factors included organizational size [16, 41] union presence [13]; environmental infrastructure [27] and national culture [27].

In the current literature, larger organizations are more likely to adopt e-HRM systems and tend to have more positive outcomes [43]. From the motivational perspective, Hussain et al. [16] examined whether organizational size was an important factor in the degree to which HR managers felt compelled to invest in HRIS to improve their strategic capabilities. They found that size was not a significant differentiator.

One additional contextual factor studied in seven of the papers is the nationality of the firm adopting the e-HRM technology. Nationality was held constant in six of the studies (Singapore, Hong Kong, Greece, Mexico, the Netherlands) and was used as an explanatory factor in one study [41]. The studies using a single-country sample 
appeared to do so for convenience of sampling, as no theoretical arguments were offered for constraining the sample in that way. It is important to note that even within these single-country studies, a large percentage of MNCs were included. To the extent that adoption and use of e-HRM occurs at the firm level, these studies may in fact represent a broader, more global sample.

In contrast, others (e.g., [41]) have argued that national context will directly affect adoption and use of e-HRM due to national differences in human resource management laws, education systems, industrial relation systems, legislation addressing storage and use of electronic data, and level of economic development. Strohmeier and Kabst [41] found rather unexpected results related to national context, as former Eastern European countries in their sample were actually more likely to have adopted e-HRM than Western European countries.

Olivas-Lujan and colleagues' [27] case studies of 4 large Mexican multinationals examined the extent to which key contextual variables, competitive environment, external telecommunications infrastructure and national cultural norms affected how eHRM was used within organizations. For example, deficient telecommunications infrastructure in more remote regions of Mexico constrained one company's use of elearning to enhance its employees' customer service skills and behaviours. Their qualitative descriptions suggest these factors might affect how e-HRM was deployed but the degree, significance, and nature of these relationships were not addressed.

Tansley and Newell [42-43] took a third approach to examining the impact of nationality on implementation of e-HRM. In their case studies, they noted that staffing implementation teams with employees from different countries increases the challenges inherent in accomplishing such an effort. Development and implementation of e-HRM is challenging enough with a cross-disciplinary team (represented by IT and HR functions) and the national diversity added another layer of complexity to the projects.

Another contextual factor that may be related to the strategic impact of e-HRM is the breadth of the technology and number of HR processes affected. The e-HRM technology reviewed in this paper ranged from single function systems for recruiting and performance appraisal to broad HRIS packages ${ }^{2}$. It seems reasonable to expect that the broader e-HRM systems have the potential for greater strategic impact. However, they may also come with more risks and technology adoption concerns.

\subsection{Levels of analysis and empirical approach}

Only eight of the studies examined macro-level questions about e-HRM and strategic HRM. The majority of the studies were focused on individual level reactions to such systems or team leader behaviors related to effective e-HRM projects [42-43]. The underlying assumption of these papers, therefore, is that there is a relationship between e-HRM and strategic HR and that individual level acceptance of e-HRM is an important issue to study. These e-HRM studies are more suited for understanding the conditions in which e-HRM will be accepted and effectively used by individual stakeholders. They cannot address the primary question of what relationship exists between e-HRM and strategic HRM.

\footnotetext{
${ }^{2}$ We intentionally excluded e-learning from this analysis, as that literature focuses more on individual learning than on the strategic benefit, data management, and user acceptance issues in the e-HRM literature.
} 
In terms of research design, six of the studies used the case study approach to examine issues around e-HRM in detail within one or just a few organizational groups. Of the remaining empirical studies, nine were cross-sectional in nature, two were longitudinal, and four were experimental. This variation in research design is generally a positive feature of this set of papers, as each approach has strengths in answering specific kinds of questions. At early stages of an area of inquiry, it can be very useful to play different approaches off one another, even alternating approaches to better understand the phenomena being studied. Unfortunately, we did not see this cross-fertilization of research approaches, with research groups pursuing a particular approach to the exclusion of others.

We also examined factors related to construct validity, internal validity, and external validity in each of the studies to help evaluate the existing evidence regarding e-HRM and strategic HRM [34]. Construct validity varied widely across the studies. Some studies used well established measures for their constructs and performed structural equation modelling to demonstrate good fit of their measurement models, giving us more confidence in their measures [e.g., 1,9,10,22,24]. Others were forced to rely on measures developed by others when using an industry-wide survey [43]. While we applaud the use of large samples across industries, it is critical to ensure that core concepts such as presence of an HR strategy are adequately measured. We also question the construct validity of some measures of e-HRM implementation [e.g., 43] including the binary measures.

Naturally, external validity was limited in the case study and experimental papers. One factor that appears to limit external validity for all the papers is differences in e-HRM systems that are not always specified. Having a clear system for describing and categorizing key features of e-HRM systems would likely help with generalizing results across situations and studies.

Finally, no studies were able to establish internal validity and therefore causal ordering at the macro-level of analysis. Of the 20 studies examined only 8 were at a macro-level of analysis and of these, only 5 provided empirical evidence for a correlational relationship between e-HRM and strategic HRM and none provided appropriate empirical support for establishing causal ordering.

\section{Discussion and Conclusions}

Our evidence-based examination of e-HRM and strategic HRM relationships across 20 studies in peer-reviewed literature over the last 2 years reveals several interesting themes for practitioners to evaluate gaps in the literature that should provoke interesting avenues for scholars to explore in future research.

\section{$5.1 \quad$ Key themes}

The majority of empirical studies concerning e-HRM and strategic HR have examined the relationship between perceived characteristics of e-HRM and perceived strategic effectiveness of the HR function or HR managers. The evidence consistently suggests there is a significant, positive relationship. All these studies depict a relationship in which e-HRM perceptions predict strategic HR effectiveness. Thus positive (negative) perceptions of e-HRM are associated with positive (negative) perceptions of HR's strategic effectiveness. Although these cross sectional and case study analyses assume the above causal ordering, there is no evidence to counter the reverse relationship. That is, it is also possible that positive (negative) perceptions of strategic HR effectiveness 
predict positive (negative) perceptions of e-HRM effectiveness. Teasing out the causal order would make a very useful and interesting contribution to this literature.

A second underlying theme in this literature is that HR managers expect e-HRM deployments to improve their strategic capabilities and enable them to become strategic business partners. Results on whether these expectations are actually realized are mixed. Early exploratory studies suggest such a strategic outcome is realized while more recent studies call this expectation into question.

A third theme is that none of the studies looked at whether e-HRM was related to other strategic outcomes such as competitive advantage, organizational performance, or improved HR outcomes such as increased human capital, reduced turnover or increased organizational commitment or job satisfaction. Instead the existing studies focus on factors one step (or more) removed from such strategic outcomes.

Finally, a fourth common theme in many of these studies is that there are important contextual factors upon which e-HRM acceptance and use by stakeholders depends. In addition to factors that might affect e-HRM acceptance by stakeholders, several studies identified contexts or resources important for e-HRM to be associated with strategic outcomes.

\subsection{Gaps and future research}

Our examination of the current published empirical research reveals at least four gaps in this research stream. The first noticeable gap in the literature is the lack of attention to strategic outcomes. We found there was generally an assumption of the strategic value of the e-HRM system, but few studies directly examined the assumption. In our opinion, this relationship is not well enough established to consider it a well-founded assumption. Thus, future research designs should consider where possible the measurement of strategic outcomes such as better knowledge management, more productive human capital, better organizational performance and so on.

The second gap we identified in the literature is a lack of longitudinal research. Only two of the 20 studies used a longitudinal design. This makes it difficult to disentangle issues of causality in the relationship between e-HRM and SHRM, as the direction of the relationship depends on the theoretical perspective underlying the study design rather than testing the relationship empirically. Interestingly, as more and more organizations adopt e-HRM and complete their implementation, we may be losing the opportunity to directly study the causal relationship between e-HRM adoption and SHRM. The time may be coming in which we need to reframe the research agenda around different characteristics of e-HRM rather than simply existence of e-HRM.

Another gap was the somewhat limited application of theory to the research questions. We considered only four of the studies we reviewed to be lacking theory altogether, but we need a stronger theoretical foundation for e-HRM research in general to help make sense of the literature, strengthen the research conducted, and facilitate effective accumulation of knowledge. The most commonly used theory across this group of studies was the technology acceptance model (TAM), a well-used theory that helps explain adoption of new technology. However, TAM is only tangentially related to strategic issues.

The last gap we see is the need for more empirical, field-based research on e-HRM and SHRM. Single organization-based case studies and experimental research accounted for nearly half (10 of 20) studies we reviewed. These approaches have helped provide a 
good foundation for future researchers to design more empirical, field-based research to test the theories and models that have been developed through case studies and experiments. This will provide a better evidence for practitioners to know what really works in practice.

\subsection{Conclusion}

In conclusion, this evidence-based review of the intersection between e-HRM and strategic HRM has led us to four primary findings in the literature: 1) implementation of e-HRM is associated with perceptions of strategic effectiveness of HR (both positive and negative), 2) there is very limited empirical evidence supporting the expectation that e-HRM s related to other strategic outcomes, 3) there is considerable evidence indicating a contextual factors are likely to be key moderators of the relationship between e-HRM and strategic HRM outcomes, and finally, 4) there are considerable gaps in the cumulative literature that need to be addressed in order to provide strong guidance to practitioners. There are many opportunities to continue and refine this important area of research, and we believe this review provides a foundation and strong motivation for moving ahead.

\section{References}

[1] Allen, D., Mahto, R.\&Otondo, R. (2007). Web-Based Recruitment: Effects of Information, Organizational Brand, and Attitudes toward a Web Site on Applicant Attraction. Journal of Applied Psychology, 92(6). 1696-1708.

[2] Alleyn, C., Kakbadse, A.\&Kakbadse, N. (2007). Using the Hr Intranet: An Exploratory Analysis of Its Impact on Managerial Satisfaction with the $\mathrm{Hr}$ Function. Personnel Review, 36(2). 295-310.

[3] Becker, B.Huselid, M.A. (1998). High Performance Work Systems and Firm Performance. Research in Personnel and Human Resources Management, 16. 53101.

[4] Bondarouk, T., Ruël, H.\&van der Heijden, B. (2009). E-Hrm Effectiveness in a Public Sector Organization: A Multi-Stakeholder Perspective. International Journal of Human Resource Management, 20(3). 578-590.

[5] Davis, F.D. (1989). Perceived Usefulness, Perceived Ease of Use and User Acceptance of Information Technology. MIS Quarterly, 13(3). 319-340.

[6] Davis, F.D., Bagozzi, R.P.\&Warshaw, P.R. (1989). User Acceptance of Computer Technology: A Comparison of Two Theoretical Models. Management Science, 35(8). 982-1003.

[7] Delery, J.E. (1998). Issues of Fit in Strategic Human Resource Management: Implications for Research. Human Resource Management Review, 8(3). 289-309.

[8] Dibbern, J., et al. (2004). Information Systems Outsourcing: A Survey and Analysis of the Literature. ACM SIGMIS Database, 35(4). 6-102.

[9] Dineen, B., et al. (2007). Aesthetic Properties and Message Customization: Navigating the Dark Side of Web Recruitment. Journal of Applied Psychology, 92(2). 356-372. 
[10] Dineen, B.Noe, R. (2009). Effects of Customization on Application Decisions and Applicant Pool Characteristics in a Web-Based Recruitment Context. Journal of Applied Psychology, 94(1). 224-234.

[11] Farndale, E., Paauwe, J.\&Hoeksema, L. (2009). In-Sourcing Hr: Shared Service Centres in the Netherlands. International Journal of Human Resource Management, 20(3). 544-561.

[12] Giddens, A. (1984). The Constitution of Society. Berkeley: University of California Press.

[13] Haines, V.Y.Lafleur, G. (2008). Information Technology Usage and Human Resource Roles and Effectiveness. Human Resource Management, 47(3). 525540.

[14] Heskitt, J.Schlesinger, L.A. (1994). Building Service, Driving Profits. Harvard Business Review, (March-April).

[15] Huselid, M.A., Jackson, S.E.\&Schuler, R.S. (1997). Technical and Strategic Human Resource Management Effectiveness as Determinants of Firm Performance. The Academy of Management Journal, 40(1). 171-188.

[16] Hussain, Z., Wallace, J.\&Cornelius, N.E. (2007). The Use and Impact of Human Resource Information Systems on Human Resource Management Professionals. Information and Management, 44. 74-89.

[17] Lengnick-Hall, M.L., et al. (2009). Strategic Human Resource Management: The Evolution of the Field. Human Resource Management Review, 19(2). 64-85.

[18] Lepak, D.A., et al. (2006). A Conceptual Review of Human Resource Management Systems in Strategic Human Resource Management Research. Research in Personnel and Human Resources Management, 25. 217-271.

[19] Lepak, D.P.Shaw, J. (2008). Strategic Hrm in North America:Looking to the Future. The International Journal of Human Resource Management, 19(8).

[20] Lepak, D.P.Snell, S.A. (1998). Virtual Hr: Strategic Human Resource Management in the 21st Century. Human Resource Management Review, 8(3). 215-234.

[21] Lukaszewski, K., Stone, D.\&Stone-Romero, E.F. (2008). The Effects of the Ability to Choose the Type of Human Resources System on Perceptions of Invasion of Privacy and System Satisfaction. Journal of Business and Psychology, 23(3/4). 73.

[22] Marler, J.H. (2009). Making Human Resources Strategic by Going to Te Net: Reality or Myth? The International Journal of Human Resource Management, 20(3). 515.

[23] Marler, J.H., Fisher, S.\&Ke, W. (2009). Employee Self-Service Technology Acceptance: A Comparison of Pre-Implementation and Post-Implementation Relationships. Personnel Psychology, 62(2). 327-341.

[24] Marler, J.H., Liang, X.\&Dulebohn, J.H. (2006). The Effect of Technology Training on Technology Acceptance. Journal of Management, 32. 721-742.

[25] Martin-Alcazar, F., Romero-Fernandez, P.M.\&Gardey, G.S. (2005). Strategic Human Resource Management:Integrating the Universalistic, Contingent, 
Configurational and Contextual Perspectives. International Journal of Human Resource Management, 15(5). 633-659.

[26] Ngai, E., et al. (2008). Importance of the Internet to Human Resource Practitioners in Hong Kong. Personnel Review, 37(1). 66-84.

[27] Olivas-Lujan, M.R., Ramirez, J.\&Zapata-Cantu, L. (2007). E-Hrm in Mexico: Adapting Innovations for Global Competitiveness. International Journal of Manpower, 28(5). 418-434.

[28] Orlikowski, W.J. (1991). The Duality of Technology: Rethinking the Concept of Technology in Organizations. Organization Science, 3(4). 398-427.

[29] Panayotopoulou, L., Vakola, M.\&Galanaki, E. (2007). E-Hr Adoption and the Role of Hrm:Evidence from Greece. Personnel Review, 36(2). 277-294.

[30] Payne, S., et al. (2009). Comparison of Online and Traditional Performance Appraisal Systems. Journal of Managerial Psychology, 24(6). 526.

[31] Pfeffer, J.Veiga, J. (1999). Putting People First for Organizational Success. Academy of Management Executive, 13(2). 37-48.

[32] Rogers, E.M. (1983). Diffusion of Innovations. Third ed. New York: Free Press.

[33] Rousseau, D.M., Manning, J.\&Denyer, D., Evidence in Management and Organization Science, in The Academy of Management Annals, J.P. Walsh and A.P. Brief, Editors. 2008, Taylor \& Francis Inc.: Philadelphia. p. 475-515.

[34] Ruël, H.J.M., Bondarouk, T.V.\&Looise, J.K. (2004). E-Hrm: Innovation or Irritation. Explorative Empirical Study in Five Large Companies on Web-Based Hrm. Management Revue, 15(3). 364-380.

[35] Ruël, H.J.M., Bondarouk, T.V.\&Van der Velde, M. (2007). The Contribution of E-Hrm to Hrm Effectiveness. Human Relations, 29(3). 280-291.

[36] Schuler, R.S. (1992). Strategic Human Resources Management: Linking the People with the Strategic Needs of the Business. Organizational Dynamics, 21(1). 18-32.

[37] Schuler, R.S.Jackson, S.E. (1987). Organizational Strategy and Organization Level as Determinants of Human Resource Management Practices. Human Resource Planning, 10(3).

[38] Snell, S., Shadur, M.A.\&Wright, P.M., Human Resources Strategy: The Era of Our Ways, in The Blackwell Handbook of Strategic Management, M.A. Hitt, R.E. Freeman, and J.S. Harrison, Editors. 2001, Blackwell Publishers Ltd.: Oxford. p. 627-649.

[39] Strohmeier, S. (2007). Research in E-Hrm: Review and Implications. Human Resource Management Review, 17(1). 19-37.

[40] Strohmeier, S. (2009). Concepts of E-Hrm Consequences: A Categorisation, Review and Suggestion. International Journal of Human Resource Management, 20(3). 528-543.

[41] Strohmeier, S.Kabst, R. (2009). Organizational Adoption of E-Hrm in Europe: An Empirical Explanation of Major Adoption Factors. Journal of Managerial Psychology, 24(6). 482. 
[42] Tansley, C.Newell, S. (2007). A Knowledge-Based View of Agenda-Formation in the Development of Human Resource Information Systems. Management Learning, 38(1). 95.

[43] Tansley, C.Newell, S. (2007). Project Social Capital, Leadership and Trust: A Study of Human Resource Information Systems Development. Journal of Managerial Psychology, 22(4). 350.

[44] Ulrich, D.Brockbank, W. (2005). Hr: The Value Proposition. Boston: Harvard Business School Press.

[45] Venkatesh, V., et al. (2003). User Acceptance of Information Technology: Toward a Unified View. MIS Quarterly, 27(3). 425-478.

[46] Voermans, M.Veldhoven, M.v. (2007). Attitude Towards E-Hrm: An Empirical Study at Philips. Personnel Review, 36(6). 887-902.

[47] Wright, P.M. (1998). Introduction: Strategic Human Resource Management Research in the 21st Century. Human Resource Management Review, 8(3). 187191.

[48] Wright, P.M., Dunford, B.B.\&Snell, S.A. (2001). Human Resources and the Resource-Based View of the Firm Journal of Management, 27. 701-721.

[49] Wright, P.M.McMahan, G.C. (1992). Theoretical Perspectives for Strategic Human Resource Management. Journal of Management, 18(2). 295-320. 